\title{
Belphégor
}

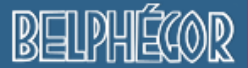

Littérature populaire et culture médiatique

18-2 | 2020

Roman Populaire Espagnol - Roman historique, 1900-1950

\section{Dumortier, Jean-Louis (éd.). « Hommage à Michel Lemoine »}

Vittorio Frigerio

\section{(2) OpenEdition \\ Journals}

Electronic version

URL: http://journals.openedition.org/belphegor/3417

DOI: 10.4000/belphegor.3417

ISSN: 1499-7185

Publisher

LPCM

Electronic reference

Vittorio Frigerio, "Dumortier, Jean-Louis (éd.). « Hommage à Michel Lemoine »", Belphégor [Online],

18-2 | 2020, Online since 16 December 2020, connection on 28 April 2021. URL: http://

journals.openedition.org/belphegor/3417 ; DOI: https://doi.org/10.4000/belphegor.3417

This text was automatically generated on 28 April 2021.

\section{(c)}

Belphégor est mis à disposition selon les termes de la Licence Creative Commons Attribution - Pas d'Utilisation Commerciale - Pas de Modification 4.0 International. 


\title{
Dumortier, Jean-Louis (éd.). « Hommage à Michel Lemoine »
}

\author{
Vittorio Frigerio
}

\section{REFERENCES}

Dumortier, Jean-Louis (éd.). « Hommage à Michel Lemoine ». Traces 22. Liège : Presses Universitaires de Liège, 2018

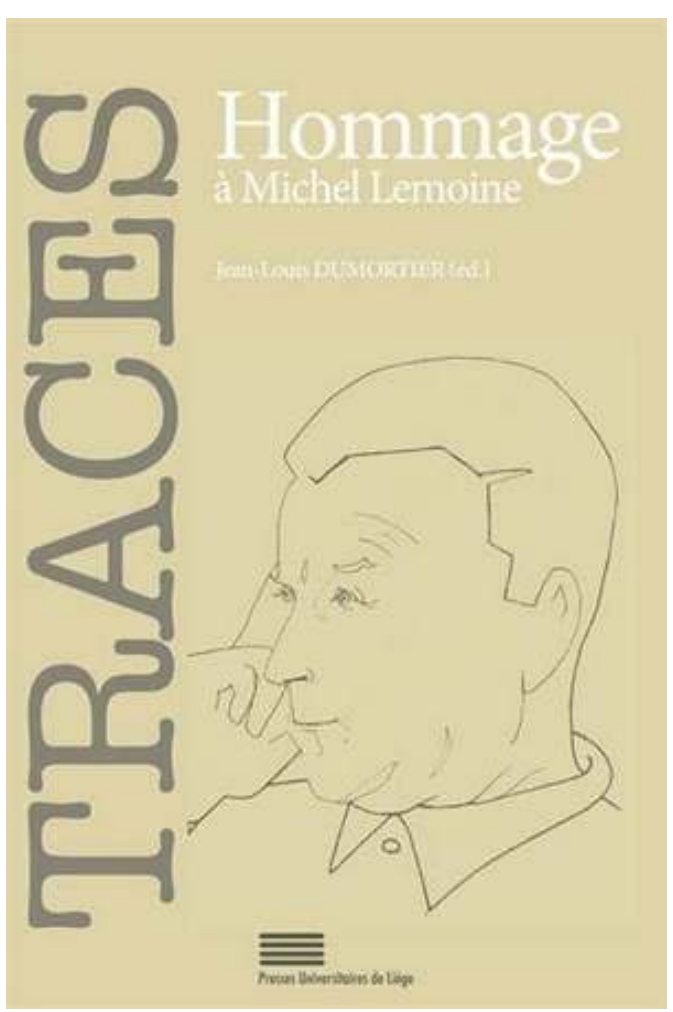


1 Les études simenoniennes, devenues progressivement plus nombreuses depuis la mort du grand romancier belge en 1989 dans sa Lausanne d'adoption, s'enrichissent régulièrement de nouveaux ouvrages ou articles éclairants, tels ceux de chercheurs passionnés comme notamment Bernard Alavoine, et bien d'autres. Cela n'est que justice, pour commémorer et apprécier à sa juste valeur cet écrivain qui a su allier une production d'une envergure inimaginable (qu'on estime à environ 400 romans) et qui a acquis une réputation internationale qui n'est égalée ou battue que par celles de monstres sacrés de la littérature (pas seulement populaire) tels Jules Verne ou Alexandre Dumas père. En plus des nouvelles recherches, on peut se réjouir aussi de voir republier, recueillis en volume, certains articles (ou contributions à des colloques) consacrés à Simenon par Michel Lemoine, un exégète fort exigeant qui a décortiqué l'œuvre du polygraphe liégeois avec une précision et une abondance de renvois parfois tout simplement stupéfiantes. C'est cette richesse et cette exactitude qui ressortent avec force à la lecture des sept études ici réunies, qui portent parfois sur ce qu'on pourrait croire des détails minuscules, négligeables, de l'œuvre de Simenon, mais qui parviennent justement à en montrer la complexité et la cohérence interne qui la caractérisent à travers une exploration systématique, nourrie par une connaissance proprement phénoménale de l'ensemble des écrits de l'auteur.

2 Dans son éditorial, qui tient lieu d'introduction, Jean-Louis Dumortier met précisément en relief les qualités du «monument d'érudition » patiemment construit par Lemoine, car il s'agit bien de cela : un travail monumental, à la fois par ce qu'il a pu coûter en lectures et recherches approfondies, et parce qu'il contribue à l'édification de ce monument posthume à Simenon, qu'il mérite pleinement, qu'est son assomption au paradis de la littérature. Elle a mauvaise presse, l'érudition, trop souvent moquée et rejetée non sans suffisance par des chercheurs qui estiment que l'utilisation d'outils théoriques à la mode et de termes abscons absout d'une familiarité superficielle et insuffisante avec l'objet prétendument analysé. Or, l'écriture de Lemoine allie au contraire clarté et modestie. Elle explique sans faire peser le poids pourtant considérable de ses connaissances. Elle arrive à se concentrer longuement sur des minuties apparentes, et à en faire patiemment le tour avec maintes références concrètes qui permettent de saisir leur signification et leur pertinence pour l'ensemble d'une œuvre qui, en dépit des mille noms d'emprunts adoptés par Simenon et de la variété de genres dans lesquels il a opéré, demeure marquée par une forte unité de caractère. Une authentique géographie simenonienne se développe ainsi à travers des articles comme "L'espace romanesque", " Simenon, la Loire et les fictions", "Simenon et l'Italie», retraçant les présences récurrentes de lieux significatifs, démasquant les allusions volontairement obscures, mettant en lumière des parcours qui transforment l'homme du nord en homme du sud et révèlent des fascinations et des tentations qu'une lecture rapide ou partielle ne saurait faire voir. Mais le goût du voyage littéraire se manifeste aussi à travers les analyses de "L'Afrique, et après?", qui montre comment un périple rapide accompli en 1932 suffit à Simenon pour construire des représentations du continent noir fort évocatrices, quoique basées plus sur une combinatoire d'éléments peu nombreux que sur une connaissance véritable. La géographie, après tout, est principalement une toile sur laquelle projeter ses désirs et ses obsessions.

3 S'il fallait indiquer une étude donnée comme particulièrement représentative de la démarche tranquille, systématique et originale de l'auteur, ce serait alors «Une 
approche des éléments campanaires chez Simenon", texte qui révélera au lecteur probablement abasourdi les mystères de la campanologie, et qui aide en même temps à formuler des hypothèses très convaincantes sur le rapport du romancier à la religion, moins étroit qu'on a pu parfois le supposer.

4 On ne peut donc qu'accueillir avec faveur l'initiative de la revue Traces de reproposer ici un choix de certains des centaines d'articles divers éparpillés par Michel Lemoine dans bon nombre de revues, "production immense », de l'avis de Jean-Louis Dumortier, qui mérite de figurer parallèlement à l'autre immense production du romancier qu'il a si fructueusement fréquenté.

\section{AUTHOR}

\section{VITTORIO FRIGERIO}

Dalhousie University 